\title{
Internet of Things: An Evolution of Development and Research area topics
}

Jorge Oliveira e Sá, João Cacho Sá ${ }^{1}$, José Luís Pereira² ${ }^{2}$ Francisco Pimenta ${ }^{3}$, Manuel Monteiro ${ }^{4}$

Ijoao.cacho@fe.up.pt, MiEEC, Faculty of Engineering of the University of Porto, 4200-465 Porto, Portugal.

2jlmp@dsi.uminho.pt, Information Systems Department, University of Minho / ALGORITMI Center, 4800-058 Guimarães, Portugal.

3 francisco.pimenta@fe.up.pt, MiEEC, Faculty of Engineering of the University of Porto, 4200-465 Porto, Portugal.

${ }^{4}$ manuel.monteiro@hpsl.pt, Hospital Particular São Lucas, Lagoa, Açores, Portugal.

\section{A R T I C L E I N F O}

Article history:

Received: 13 December, 2016

Accepted: 18 January, 2017

Online: 28 January, 2017

Keywords:

Alliance for the Internet of Things

Innovation

European Research Cluster on

the Internet of Things

IoT Research Roadmap

Strategic Research Agenda

European Union

Innovation

\begin{abstract}
A B S T R A C T
Internet of Things (IoT) is a hot topic in the Europe Union (EU). In the year of 2015 the EU established an Alliance of Internet of Things Innovation (AIOTI) and this alliance included the IoT European Research Cluster (IERC) on the Internet of Things in the work group 01. IERC was established in 2007 and addresses the large potential for Internet of Thingsbased capabilities in Europe and to coordinate the convergence of ongoing activities. This organization regularly publishes Strategic Research Agendas with short, medium and long term forecasts of development and research topics. The aim of this paper is to study these Strategic Research Agendas published in the years 2010, 2011, 2012, 2014 and 2016 and make an identification of topics, in order to understand its evolution over time in terms of areas that have already been researched (or the research has already started) as well as those not yet explored. This work was performed based on a literature review methodology to identify the evolution in all the Strategic Research Agendas published in the years of 2010, 2011, 2012, 2014 and 2016.
\end{abstract}

\section{Introduction}

The creation by the European Union (EU) of the European Research Cluster on the Internet of Things (IERC) in the year of 2007, was provided due to the need to bring together EU-funded projects in this area, thereby trying to define a common vision as well as define Internet of Things (IoT) [1]. However, the objectives of IERC are broader, as it aims to create and develop insight into IoT research activities in Europe, as well as to define a strategy for cooperation with non-European entities in the IoT area.

More recently EU established an Alliance for Internet of Things Innovation (AIOTI) in March 2015 with the purpose of supporting the development of the most dynamic and agile IoT ecosystem and industry in the world. This ecosystem, built on the work of the IoT European Research Cluster (IERC), seeks to spill over innovation across industries and business sectors of IoT transforming ideas into solutions and business models [2].

*Corresponding Author: Jorge Oliveira e Sá, Information Systems Department, University of Minho /ALGORITMI Center, 4800-058 Guimarães, Portugal, jos@dsi.uminho.pt
Other objectives of the AIOTI include: fostering experimentation, replication, and deployment of IoT and supporting convergence and interoperability of IoT standards; gathering evidence on market obstacles for IoT deployment; and mapping and bridging global, EU, and member states' IoT innovation activities.

In this way, IERC has published Strategic Research Agendas (SRAs) since 2010, which intend to give a list of fields to be developed and researched as well as the paths for the future. These agendas have been updated according to the problems found in the investigations carried out. This work intends to make a comparison between the first SRA published in 2010, with the SRAs of 2011, 2012, 2014 and particularly with the SRA published in 2016. This comparative analysis intends to show the evolution of the topics proposed during this time period.

This work has a methodology based on literature review in the several SRAs proposed by IERC, intends to answer the question "What is relevant to research in IoT?" 
Thus, in section 2 of this paper the definition of IoT is presented, in section 3 a brief explanation of AIOTI is presented and in section 4 the various SRAs published by IERC will be presented. SRAs were published in the years 2010 SRA [3], 2011 SRA [4], 2012 SRA [5], 2014 SRA [6] and 2016 SRA [2]. In this section the topics related to the area of technological development as well as the topics related to the research area will be mentioned, due to the extension of the goals of each topic it is not possible to detail them, however, the number of changes / evolutions that have suffered is presented and discussed. In section 5 it will be carried out the comparison between the different SRAs, it is intended to identify topics that are interesting to both academic and research communities. Section 6 will contain the conclusions.

\section{Internet of Things definition}

Although IoT is a recent buzzword, it was nicknamed this way for the first time in 1999 by [7]. However, the concept was developed many years earlier, in the early 1980s, by a group of programmers at Carnegie Melon University who modified a Coca-Cola machine by linking it to the Internet to obtain information on the availability of the drink and the time that the bottle spent inside the machine to ensure that the beverage was chilled and thus prevent them from making the trip in vain [8]. It is a simple example, but it explains the concept.

[7] refers that "today computers - and, therefore, the internet are almost wholly dependent on human beings for information. Nearly all of the roughly 50 petabytes (a petabyte is 1,024 terabytes) of data available on the Internet were first captured and created by human beings - by typing pressing a record button, taking a digital picture or scanning a bar code. Conventional diagrams of the Internet include servers and routers and so on, but they leave out the most numerous and important routers of all people. The problem is, people have limited time, attention and accuracy - all of which means they are not very good at capturing data about things in the real world".

The IERC definition states that IoT is "A dynamic global network infrastructure with self-configuring capabilities based on standard and interoperable communication protocols where physical and virtual 'things' have identities, physical attributes, and virtual personalities and use intelligent interfaces, and are seamlessly integrated into the information network" [9].

\section{Alliance for Internet of Things Innovation}

The AIOTI was formally launched on the 26th of March 2015, in the past year the Alliance has successfully contributed to convergence and interoperability of IoT standards, as well as the Digitizing European Industry policy. To achieve the remainder of its mission the Alliance plans to engage with building IoT Innovation Ecosystems from the ground up, and to establish communication channels with startup ecosystems, early adopter communities, European regions, global IoT initiatives and new potential markets [10].

The AIOTI is divided in the following groups: Management Board (MB), General Assembly (GA), Working Groups (WG) and Steering Groups (SG).

There are thirteen WGs, see Figure 1, divided in four horizontal and nine vertical groups, with a Chair and a Co-Chair, nominated and elected by that WG's members. Every WG elects one representative for the $\mathrm{SG}$.
The SG members are the WG Chairs. They are assigned for a period of two years, to a maximum of six (three periods). The EU Commission is a special member.

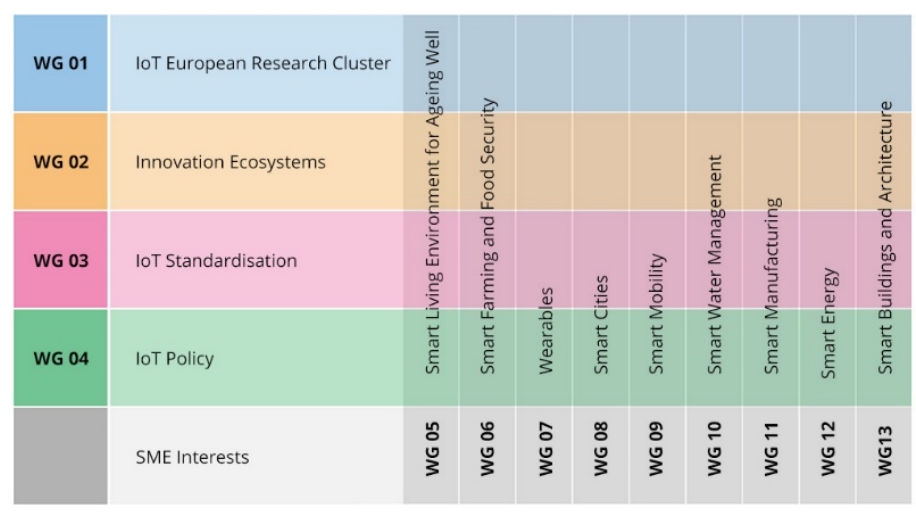

Figure 1 - AIOTI Working Groups [10]

WG 01 - IoT European Research Cluster, the IERC compares EU-funded innovation research and development programs, with the aim of defining a common vision of IoT technology and addressing European research challenges.

WG 02 - Innovation Ecosystems, this WG aims at designing actions to develop innovation ecosystems by stimulating startups, encouraging the use of open IoT platforms, enabling Large Scale Pilots, and linking large and small companies through open innovation.

WG 03 - IoT Standardization, this WG identifies and, where appropriate, makes recommendations to address existing IoT standards, analyses gaps in standardization, and develops strategies and use cases aiming for (1) consolidation of architectural frameworks, reference architectures, and architectural styles in the IoT space, (2) interoperability and (3) personal data \& personal data protection to the various categories of stakeholders in the IoT space.

WG 04 - IoT Policy, this WG identifies, and, where appropriate, makes recommendations to address existing and potential barriers that prevent or hamper the take-up of IoT in the context of the Digital Single Market.

WG 05 - Smart living environment for ageing well, the topic for this WG refers to smart homes and smart living environments that can support vulnerable people, such as, but not limited to elderly or disabled people, in staying active, independent and out of institutional care settings, also leading to reduced costs for care systems and better quality of life for vulnerable categories of citizens. The WG deliverables include white papers, recommendation reports and innovative use cases susceptible to improve the quality of life of Elderly people using the latest IoT technologies.

WG 06 - Smart Farming and Food Security, the topic of this WG refers to IoT scenarios/use cases that allow monitoring and control of the plant and animal products life cycle "from farm to fork".

WG 07 - Wearables, the topic for this WG refers to IoT solutions that integrate key technologies (e.g. nano electronics, organic electronics, sensing, actuating, communication, low power computing, visualization and embedded software) into intelligent systems to bring new functionalities into clothes, other fabrics, patches, watches and other body-mounted devices. The WG 
focuses its work on healthcare, well-being, safety, security and infotainment applications.

WG 08 - Smart Cities - the topic for this WG refers to IoT solutions used by a city in order to enhance performance, safety and wellbeing, to reduce costs and resource consumption, and to engage more effectively and actively with its citizens. Key 'smart city' sectors may include transport, energy, healthcare, lighting, water, waste and other city related sectors.

WG 09 - Smart Mobility, the topic for this WG refers to IoT solutions that allow for increased multi-modal mobility, more efficient traffic management, a dynamic road infrastructure, automated road tolling, usage based insurance and improved policy making through the analysis of road usage data provided by smart vehicles including autonomous and connected cars.

WG 10 - Smart Water Management, the topic for this WG refers to IoT solutions that improve water management efficiency by monitoring and controlling surface water retention, flooding etc.

WG 11 - Smart Manufacturing, the topic for this WG refers to IoT solutions that bring together information, technology and human ingenuity to achieve a rapid revolution in the development and application of manufacturing intelligence to every aspect of business.

WG 12 - Smart Energy, the topic for this WG refers to IoT solutions deployed by various companies along the value chain (i.e. IoT technology providers, energy companies (in generation, supply, grid and market participants, traders, aggregators, etc.) to allow the performance optimization of their energy asset portfolios (Renewables plants, Grid Substations, Control Rooms, Prosumer Demand Responsive Loads and EV Charging infrastructures).

WG 13 - Smart Building and Architecture, the topic of this WG is the IoT technologies and solutions deployed in buildings and districts of buildings to improve life of the occupant by addressing and optimizing elements such as comfort, light, temperature, air quality, water, nourishment, fitness, and energy usage.

\section{European Research Cluster on the Internet of Things}

The European Union (EU) started the IERC due to the need to unite projects funded by the EU in the IoT area. The IERCs main purpose is to define a common vision as well as the technologies for IoT [1]. But IERC goals are more embracing because it aims to create and develop a unified vision of all the research on IoT in Europe as well as a cooperation strategy with non-European entities in the IoT field.

The IERC has made available Strategic Research Agendas (SRAs) since 2010 to achieve its goal. These SRAs aim to select research fields as paths for the future.

The SRAs were published in the last years and they have suffered constant updates. The first SRA was released in 2010 and more have been issued in 2011, 2012, 2014 and 2016. Since each SRA has many topics and objectives, it is not possible to describe them in detail but it is possible to define the changes/updates that they suffered in terms of dimension.

The creation of the SRAs by the IERC through the years allowed the identification of a group of areas that are needed to implement successfully IoT in Europe in both short term and long term. Since some of these areas weren't successfully implemented in the SRA they were planned initially, they have been postponed into latter SRAs. The SRAs divide two areas among what needs "Research" and what needs "Development". In this section it will only be given relevance to new topics or new objectives for topics that have been issued in the different published SRAs.

\subsection{SRA}

This was the first SRA to be issued by the IERC two years after the creation of the work team that starter working in the initial concept of IoT. In this first SRA it is done a survey of the areas in which the IoT is or may be present and also identify the areas that deserve greater attention by the practitioners and research community.

The 2010 SRA became the foundation for the remaining SRAs that were published in the following years. The SRA identifies, separately, what needs to be "Development" at the technological level and what needs to be "Research" in order to address existing needs.

In the "Development" area, more precisely in the technological level, there were identified twelve topics, namely: (1) Identification Technology, (2) IoT Architecture Technology, (3) Communication Technology, (4) Network Technology, (5) Software and Algorithms, (6) Hardware Devices, (7) Data and Signal Processing Technology, (8) Discovery and Search Engine Technologies, (9) Power and Energy Technologies, (10) Security, Privacy \& Trust Technologies, (11) Material Technology and (12) Standardization.

In the "Research" area there were identified fifteen topics, namely: (1) Identification Technology, (2) IoT Architecture, (3) SOA Software Services for IoT, (4) IoT Architecture Technology, (5) Communication Technology; (6) Network Technology; (7) Software and Algorithms, (8) Hardware Devices, (9) Hardware Systems, Circuits and Architectures, (10) Data and Signal Processing Technology, (11) Discovery and Search Engine Technologies, (12) Power and Energy Technologies, (13) Security, Privacy \& Trust Technologies, (14) Material Technology, (15) Standardization.

These topics are divided chronologically by four temporal periods: the first is the time period before 2010 , the second is in an interval of years between 2010 and 2015, the third period is in another interval of years between 2015 and 2020 and finally the last period corresponds the years beyond 2020. This SRA is the only one that incorporated the time period before 2010 , so this time period is not considered in this study.

\subsection{SRA}

This SRA continues the work carried out by the previous SRA (2010), since only one year passed from its publication. However, the time periods applied in this SRA were adjusted to the date when it was published (2011), thus the first period corresponds to the years from 2011 to 2015 , the second from 2015 to 2020 and finally the third time period is beyond 2020 .

In this SRA the most of the topics have remained unchanged. However, three topics have undergone changes, one in "Development" at the technological level, the topic (6) Hardware Devices has incorporated the addition of another goal for the interval of the years 2011 to 2015, this goal consists of the integration of NFC in mobile phones and Sensors. The other two in "Research", to the time period 2011-2015, the topic (1) Identification Technology has incorporated a new goal (Convergence of IP and IDs and addressing scheme) and the topic 
(6) Network Technology has incorporated another goal, this goal consists of incorporating systems based on RFID sensors.

The three new goals were the only ones to be added in all the time periods present in the 2011 SRA [3].

\section{3. $2012 S R A$}

In this SRA it is possible to identify some differences in relation to the previous SRAs, mainly due to the development and research in IoT being more mature, since two years have passed since the launching of the 2010 SRA. Once again, the temporal periods used in this SRA have been adjusted to the date it was published (2012). The time periods are: years between 2012 and 2015, years between 2016 and 2020; and maintaining the same period of previous SRAs, i.e., beyond the year 2020 .

Since the knowledge about the IoT topic increases, new topics are likely to emerge. Thus, in this SRA, there are seven new topics that are divided as follows: two new topics for "Development" and five new topics for "Research".

However, the 2012 SRA is not only marked by the introduction of new topics, but also by giving great relevance to security technologies for IoT.

In addition to the new topics, in this SRA are added twenty-eight new goals distributed across different areas and topics, in addition to being distributed over different time periods.

In the "Development" area are twenty-four new goals. Of these, twelve arise for the time period from 2012 to 2015 and are distributed by the topics as follows: one in (5) Software and Algorithms; two in (6) Hardware; one in (12) Standardization; and three in (10) Security, Privacy \& Trust Technologies, the others five goals are in the new topics (13) IoT Infrastructure and (14) IoT Applications. Eight goals goes to the time period of 2016-2020 and are three to the topic (10), one for the topic (12) and four to the new topics (13) and (14). The remaining four goals goes to the time period 2015-2020, one goes to the topic (10), one goes to the topic (11) Material Technology, and two goes to the new topics (13) and (14).

In the "Research" area arise thirty-eight new goals of which twenty of them are present in the time period between 2012 and 2015, namely: one in (9) Hardware Systems, Circuits and Architectures; two in (3) SOA Software Services for IoT; and seven are present in (13) Security, Privacy \& Trust Technologies, the remaining ten are in the new topics (16) IoT Infrastructure, (17) IoT Applications, (18) Societal Responsibility, (19) Governance (Legal Aspects), and (20) Economic. Twelve goals are present in time period 2016-2020 and one is in the topic (3), another one in topic (9), four in topic (13) and six in the new topics (16), (17), (18) and (19). In the time period beyond 2020, are the remaining six goals, one in topic (3), two in topic (13), one in topic (14) Material Technology, and the last two in the new topics (16) and (17) [4].

\subsection{SRA}

In this SRA arouse a new topic named Interoperability. It appeared in both the "Development" area in which it is numbered as the topic (15) and in the "Research" area, in which it becomes topic (21).

This SRA has only two time periods, one is the time period 2015-2020 and the other is beyond 2020. Thus is more difficult to compare this SRA with the previous. However each topic has different number of goals from the 2012 SRA.

In the "Development" area the topic (1) Identification Technology had seven goals in 2012 and now has six. Topic (2) IoT Architecture Technology changed from eight to six goals. Topic (3) Communication Technology augmented from seven to eight goals. Topic (4) Network Technology diminished from eight to seven goals. Topic (5) Software and Algorithms changed from twelve to thirteen goals. Topic (6) Hardware reduced from nine to five goals. Topic (7) Data and Signal Processing Technology changed from four to three goals. Topic (8) Discovery and Search Engine Technology changed from five to four goals. Topic (9) Power and Energy Storage Technology changed from nine to seven goals. Topic (10) Security, Privacy and Trust Technology reduced from fourteen to ten goals. Topic (11) Material Technology changed from five to four goals. Topic (12) Standardization decreased from seven to five goals. Topic (13) IoT Infrastructure changed from seven to six goals. Topic (14) IoT Applications increased from four to eight goals. The new topic (15) Interoperability has five goals.

In the "Research" area the topic (1) Identification Technology has seven goals in 2012 and now has six. Topic (2) IoT Architecture change from two to one goal. Topic (3) SOA Software Services for IoT reduced from six to four goals. Topic (4) IoT Architecture Technology change from thirteen to twelve goals. Topic (5) Communication Technology augment from eight to eleven goals. Topic (6) Network Technology change from fourteen to thirteen goals. Topic (7) Software and Algorithms maintain the same fourteen goals. Topic (8) Hardware Devices reduce from twenty-three to seventeen goals. Topic (9) Hardware Systems, Circuits and Architectures reduced from twenty to fourteen goals. Topic (10) Data and Signal Processing Technology maintain the same five goals. Topic (11) Discovery and Search Engine Technology maintain the same seven goals. Topic (12) Power and Energy Storage Technology reduce from ten to six goals. Topic (13) Security, Privacy and Trust Technology reduced from twenty to sixteen goals. Topic (14) Material Technology change from seven to four goals. Topic (15) Standardization has zero goals, so this topic is no long be considered. Topic (16) IoT Infrastructure change from six to five goals. Topic (17) IoT Applications increase from five to nine goals. Topic (18) Societal Responsibility has zero goals, so this topic is no long be considered. Topic (19) Governance (Legal Aspects) maintains the same three goals. Topic (20) Economic change from one to two goals. Finally, the new topic (21) Interoperability has three goals [5].

\subsection{SRA}

This is the last SRA published. This SRA the topic Material Technology in "Development" - topic (11) and "Research" - topic (14) has zero goals.

In "Development" area, to the time period of 2016-2020, four topics increase in seven the number of goals, one in the topic (2) IoT Architecture Technology, one in topic (5) Software and Algorithms, two in topic (3) Communication Technology and three in topic (14) IoT Applications. For the time period beyond 2020, five topics increase the number of goals, topic (1) Identification Technology has a new goal, topic (3) has one new goal, topic (10) Security, Privacy and Trust Technology has three new goals, topic (14) has ten new goals and topic (15) Interoperability has one more goals. 
In "Research" area, to the time period of 2016-2020, eight topics change their number of goals, five new goals to topic (3) SOA Software Services for IoT, reduction from twelve to ten goals in topic (7) Software and Algorithms, two more goals in topic (8) Hardware Devices, one more goal in topic (9) Hardware Systems, Circuits and Architectures, two more goals in topic (10) Data and Signal Processing Technology, reduction of one goal in topic (17) IoT Applications, increase of two goals in topic (19) Governance (Legal Aspects), and one more goal in topic (20) Economic [2].

\section{Discussion of SRA evolution}

To the "Development" area, all topics and number of goals are presented in Table 1. So, in this table, it is possible to see the evolution of the goals that each topic underwent throughout the various SRAs. The first line represents all the topics published, the columns represent the fifteen topics and the lines represent the five SRAs (2010, 2011, 2012, 2014 and 2016) to each one it is presented the various time periods. Each cell on the table contains a number that represents the number of goals that each topic had in each SRA (time period), and a hyphen (-) means that the topic was not covered in the specific SRA and time period.

In Table 1 the topic (14) IoT Applications is to be highlighted because this topic has only been included in the 2012 SRA with four goals and in the 2016 SRA this topic had twenty-one goals, which is the biggest value in the last SRA. There are other two topics with high importance, topic (3) Communication Technology with a growth in 2016 from eight to twelve goals and topic (10) Security, Privacy and Trust Technology that presented fourteen goals in 2012, now presents a growth from ten to thirteen goals since the 2014 SRA. Topic (5) Software and Algorithms has a high and constant number (12-13 goals) in all SRAs. The other topics have an almost constant number of goals in the five SRAs, see Figure 2.

Analyzing Table 2, that concerns the "Research" area, comparing the 2010 SRA to the 2011 SRA it is verified that the 2011 SRA presents a greater concern in defining some topics that were not defined in the year of 2010, as is the case of topic (6) Network Technology that was adapted to the reality of the area of IoT $[2,3]$.

Comparing now the 2011 SRA and 2012 SRA it can be concluded that the 2012 SRA presented five new topics. When analyzing the topics that are being added we can verify the existence of the first concerns regarding the impact of the implementation of IoT in the society, e.g., topics like (17) IoT
Applications, (18) Societal Responsibility, (19) Governance (Legal Aspects) and (20) Economics. Through the observation of the goals that appear in this SRA, it can be concluded that the goals are related to two subjects, namely: processes, with the creation of infrastructures / standards that allow the integration of IoT; and the use in an industrial environment through the use of sensors. Related to topic (13) Security, Privacy and Trust Technology, there are a greater number of goals that focus on privacy techniques to remain anonymous, techniques that ensure users' privacy as well as their data, new methods for assessing trust in devices and data and methods to ensure platform and data security. However, in 2012 SRA there is a situation that needs to be emphasized, which consists in the suppression of the topic (15) Standardization, this is justified by the redefinition and new placement of the topic (15) goals to other topics $[3,4]$.

Table 1 - "Development" Area

\begin{tabular}{|c|c|c|c|c|c|c|c|c|c|c|c|c|c|c|c|c|}
\hline \multirow[t]{2}{*}{ SRAs } & Topic & \multirow[t]{2}{*}{ 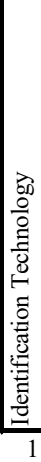 } & 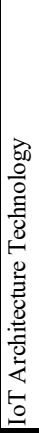 & 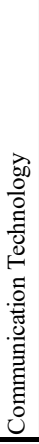 & 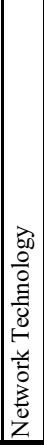 & 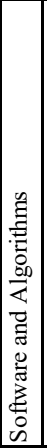 & \multicolumn{2}{|c|}{ 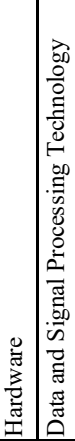 } & 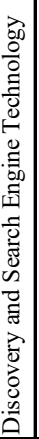 & 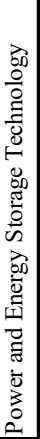 & 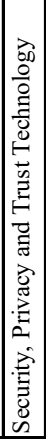 & 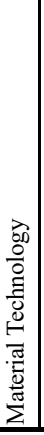 & 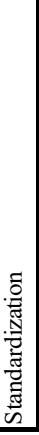 & 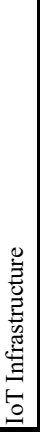 & 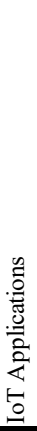 & 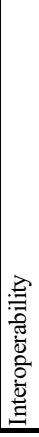 \\
\hline & & & 2 & 3 & 4 & 5 & 6 & 7 & 8 & 9 & 10 & 11 & 12 & 13 & 14 & 15 \\
\hline \multirow{3}{*}{ SRA 2010} & $2010-2015$ & 3 & 4 & 5 & 5 & 4 & 3 & 2 & 2 & 3 & 3 & 3 & 3 & - & - & - \\
\hline & 2015-2020 & 3 & 2 & 1 & 1 & 3 & 2 & 1 & 1 & 4 & 3 & 1 & 1 & - & - & - \\
\hline & Bey ond 2020 & 1 & 2 & 1 & 2 & 5 & 1 & 1 & 2 & 2 & 1 & - & 1 & - & - & - \\
\hline \multirow{3}{*}{ SRA 2011} & 2011-2015 & 3 & 4 & 5 & 5 & 4 & 4 & 2 & 2 & 3 & 3 & 3 & 3 & - & - & - \\
\hline & 2015-2020 & 3 & 2 & 1 & 1 & 3 & 2 & 1 & 1 & 4 & 3 & 1 & 1 & - & - & - \\
\hline & Bey ond 2020 & 1 & 2 & 1 & 2 & 5 & 1 & 1 & 2 & 2 & 1 & - & 1 & - & - & - \\
\hline \multirow{3}{*}{ SRA 2012} & $2012-2015$ & 3 & 4 & 5 & 5 & 5 & 6 & 2 & 2 & 3 & 6 & 3 & 4 & 3 & 2 & - \\
\hline & 2016-2020 & 3 & 2 & 1 & 1 & 3 & 2 & 1 & 1 & 4 & 6 & 1 & 2 & 3 & 1 & - \\
\hline & Bey ond 2020 & 1 & 2 & 1 & 2 & 5 & 1 & 1 & 2 & 2 & 2 & 1 & 1 & 1 & 1 & - \\
\hline \multirow{2}{*}{ SRA 2014} & $2015-2020$ & 5 & 4 & 6 & 4 & 6 & 4 & 2 & 2 & 5 & 8 & 2 & 4 & 4 & 6 & 4 \\
\hline & Bey ond 2020 & 1 & 2 & 2 & 3 & 6 & 1 & 1 & 2 & 2 & 2 & 2 & 1 & 2 & 2 & 1 \\
\hline \multirow{2}{*}{ SRA 2016} & $2016-2020$ & 5 & 5 & 8 & 4 & 7 & 4 & 2 & 2 & 5 & 8 & - & 4 & 4 & 9 & 4 \\
\hline & Bey ond 2020 & 3 & 2 & 3 & 3 & 6 & 1 & 1 & 2 & 2 & 5 & - & 1 & 2 & 12 & 2 \\
\hline
\end{tabular}

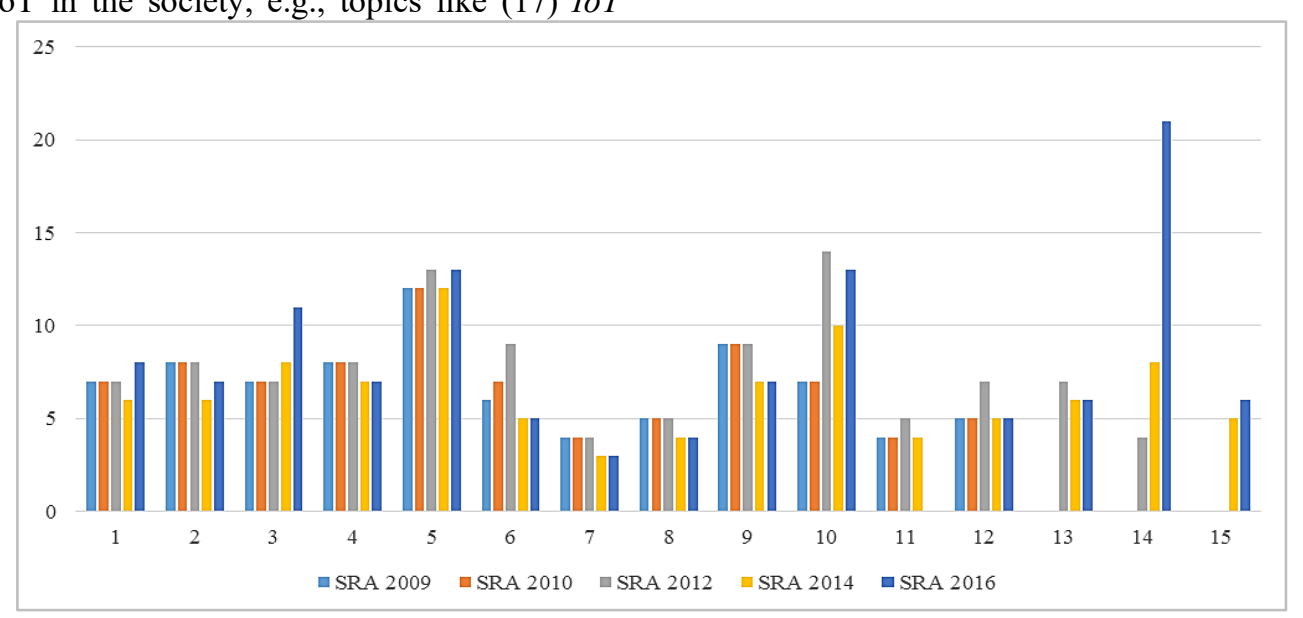


The comparison between years 2012 and 2014 will be carried out, the latter is already focused on the time period from 2015 to 2020. In this comparison the number of goals that are delayed between the 2012 SRA and 2014 SRA will be verified. In the 2014 SRA a total of one hundred and twenty-two goals (122) are identified. These goals are spread over nineteen topics for the time period between 2015 and 2020, with forty-seven of these goals being carried over from the previous time period, because they were not fulfilled in a timely manner, and twenty-eight new goals have emerged. There are two topics that stand out: (17) IoT Applications, which includes mobile applications for IoT; and (5) Communications Technology which includes the new networks, as is the case of 5G referenced in the goals of the 2014 SRA. In the 2014 SRA the topic (18) Social Responsibility disappears, however its goals were not distributed to other topics with the justification that they cannot be applied while IoT does not reach a higher maturity $[4,5]$.

Lastly, it will be carried out the comparison between the years 2014 and 2016. The first highlight is that the number of goals increased from one hundred forty-eight (148) to one hundred eighty-two (182) that represents a growth of thirty-four goals. This happens essentially in the time period of beyond 2020 . Generally all topics increased the number of goals for all time periods, but in the time period of beyond 2020 the number of goals increased from thirty in 2014 SRA to fifth-three in 2016 SRA, which represents an increase rate of $77 \%$. However, the topic (14) Material Technology was suppressed. It is concluded that the 2016 SRA presents a higher number of goals comparing with the previous SRAs and the justification for this growth is the higher number of goals for almost all topics in the time period of beyond $2020[5,6]$. These numbers may be seen at Figure 3 .

Table 2 - "Research" Area

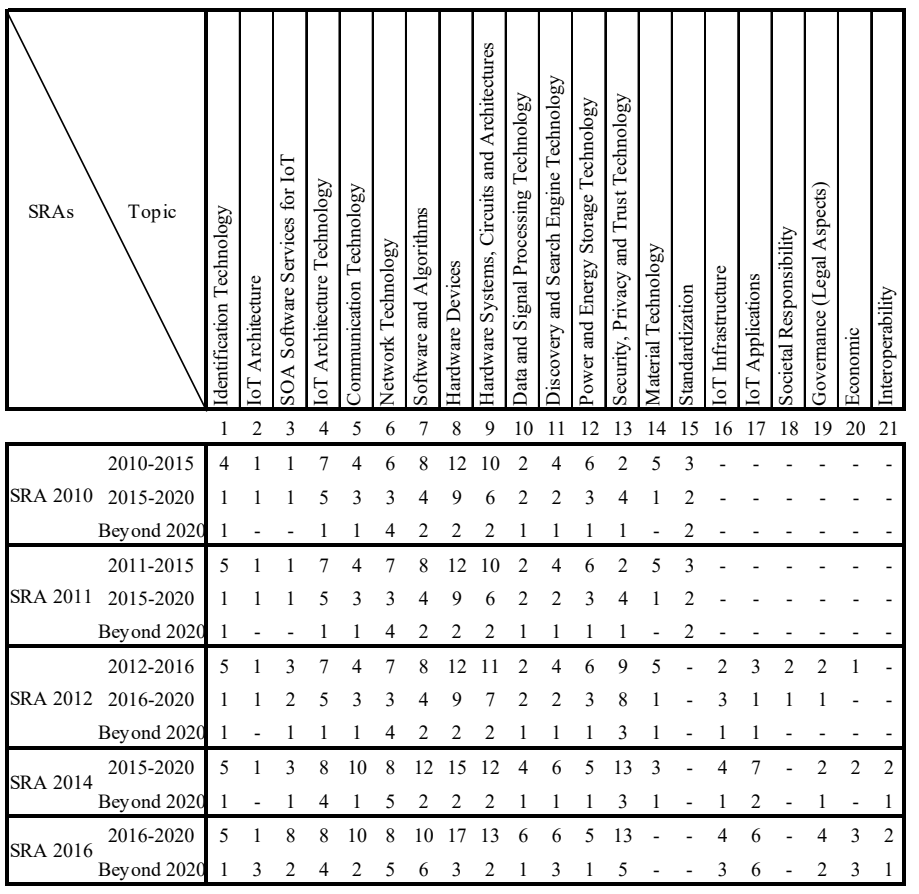

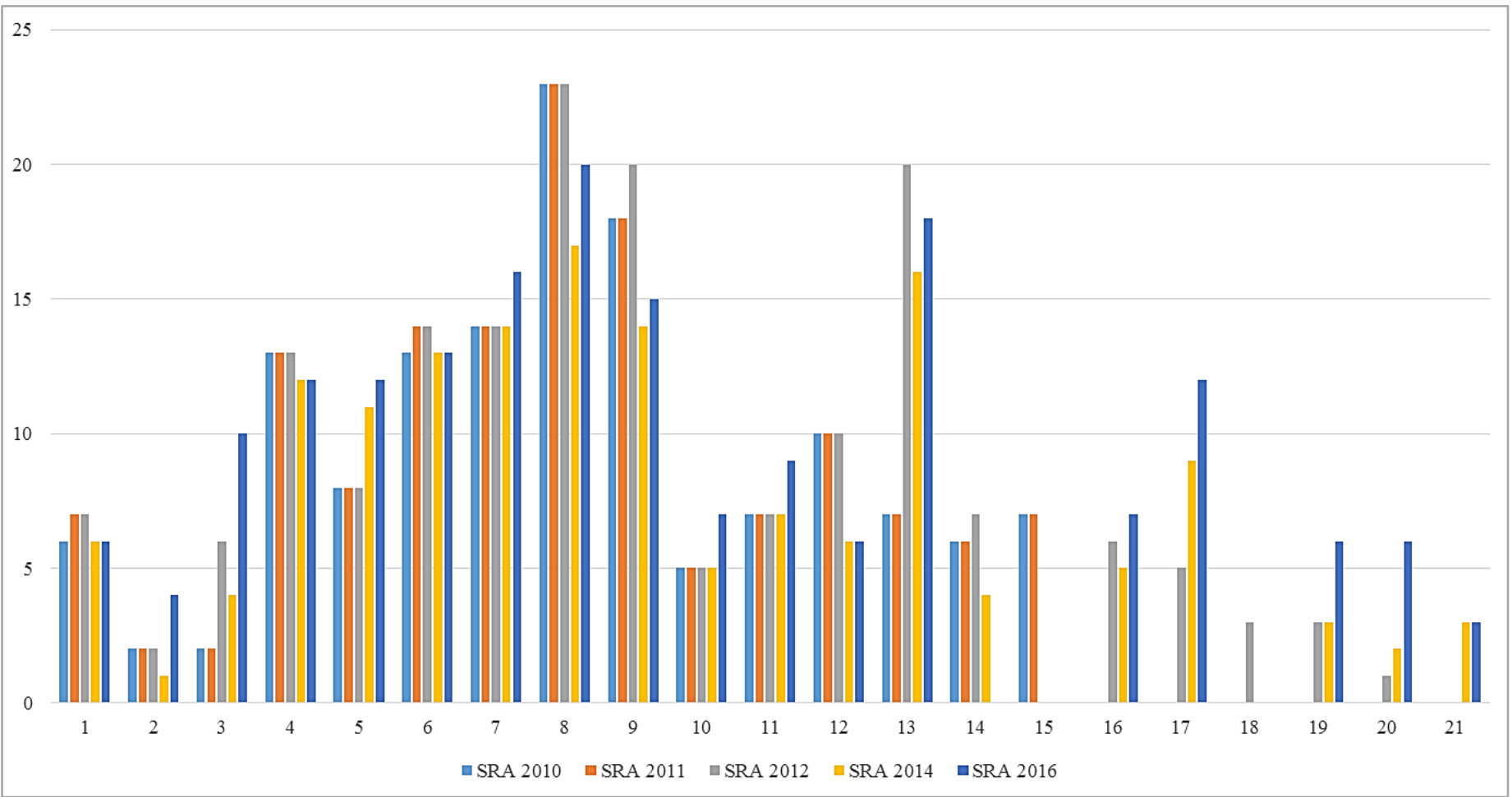


The Table 3 compares the numerical representation of goals in all topics in both areas "Development" and "Research". The interpretation of this table is similar to Table 1 and 2 . When a topic does not exist in one area (i.e., not has any goal) it is represented by a hyphen (-). If the topic has goals, it is represented by two numbers, the first number belongs to the "Development" area and the second number concerns the "Research" area, e.g., (3/1).

From this study it is identified that there are relevant topics for those who want to research in IoT subject. It is not intended to carry out research on "Development" area, since it is considered that the market already responds or will respond to the needs of IoT. In the "Research" area, the topic (21) Interoperability is one of the most important in IoT, because "things" need protocols to communicate with other "things", to accomplish this there is a need for an IoT Architecture (topic 2). In this IoT ecosystem there is the need for providing services (topic 3 SOA Software Services for IoT). These services are delivered by IoT Applications (topic 17). These applications will be executed on Hardware devices (topic 8) in a secure way, (topic 13 Security, Privacy \& Trust Technologies) and should return value (topic 20 Economic). It is considered that these topics may be relevant to research, especially in the actual state of maturity of IoT. Regarding the topics (18) Societal Responsibility and (19) Governance (legal aspects) could also be considered, but as mentioned above IoT has not yet reached the state of maturity necessary to consider these topics $[5,6]$.

Table 3 - Development and Research Area

\begin{tabular}{|c|c|c|c|c|c|c|c|c|c|c|c|c|c|c|c|c|c|c|c|c|c|c|}
\hline SRAs & & 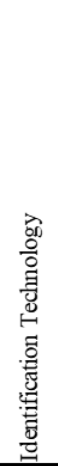 & 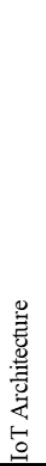 & 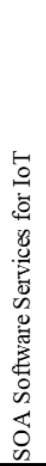 & 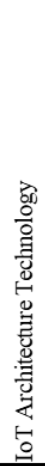 & 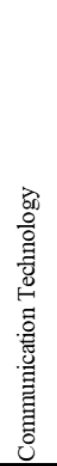 & 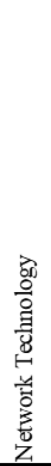 & 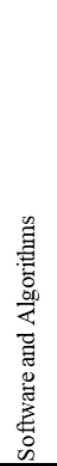 & 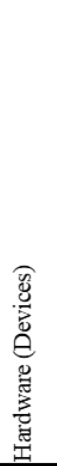 & 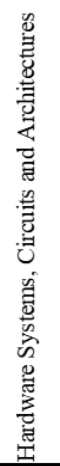 & 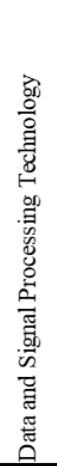 & 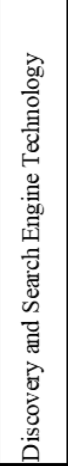 & 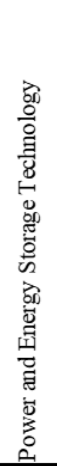 & 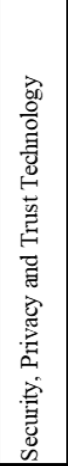 & 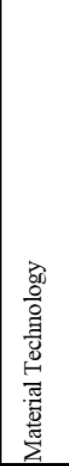 & 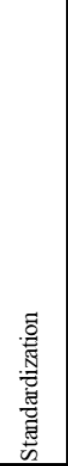 & 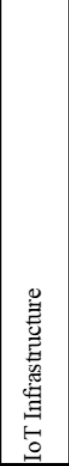 & 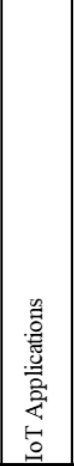 & 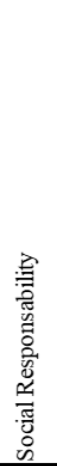 & 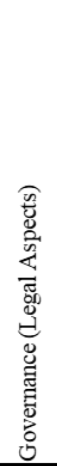 & 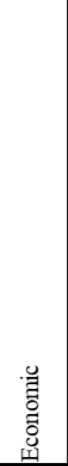 & 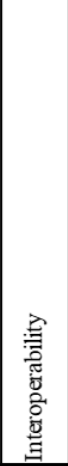 \\
\hline \multicolumn{2}{|c|}{ Development/Research } & $1 / 1$ & $-/ 2$ & $-/ 3$ & $2 / 4$ & $3 / 5$ & $4 / 6$ & $5 / 7$ & $6 / 8$ & $-/ 9$ & $7 / 10$ & $8 / 11$ & $9 / 12$ & $10 / 13$ & $11 / 14$ & $12 / 15$ & $13 / 16$ & $14 / 17$ & $-/ 18$ & $-/ 19$ & $-/ 20$ & $15 / 21$ \\
\hline SRA 2010 & $2010-2015$ & $3 / 4$ & $-/ 1$ & $-/ 1$ & $4 / 7$ & $5 / 4$ & $5 / 6$ & $4 / 8$ & $3 / 12$ & $-/ 10$ & $2 / 2$ & $2 / 4$ & $3 / 6$ & $3 / 2$ & $3 / 5$ & $3 / 3$ & $-/$ & $-/$ & -1 & $-/$ & $-/$ & $-/-$ \\
\hline \multirow[t]{2}{*}{ SRA 2011} & $2015-2020$ & $3 / 1$ & $-/ 1$ & $-/ 1$ & $2 / 5$ & $1 / 3$ & $1 / 3$ & $3 / 4$ & $2 / 9$ & $-/ 6$ & $1 / 2$ & $1 / 2$ & $4 / 3$ & $3 / 4$ & $1 / 1$ & $1 / 2$ & $-/-$ & $-/-$ & $-/$ & $-/-$ & $-/-$ & $-/-$ \\
\hline & Bey ond 2020 & $1 / 1$ & $-/-$ & $-/-$ & $2 / 1$ & $1 / 1$ & $2 / 4$ & $5 / 2$ & $1 / 2$ & $-/ 2$ & $1 / 1$ & $2 / 1$ & $2 / 1$ & $1 / 1$ & $-/$ & $1 / 2$ & $-/-$ & $-/-$ & $-/$ & $-/-$ & $-/-$ & $-/-$ \\
\hline \multirow{3}{*}{ SRA 2012} & $2012-2016$ & $3 / 5$ & $-/ 1$ & $-/ 3$ & $4 / 7$ & $5 / 4$ & $5 / 7$ & $5 / 8$ & $6 / 12$ & $-/ 11$ & $2 / 2$ & $2 / 4$ & $3 / 6$ & $6 / 9$ & $3 / 5$ & $4 /-$ & $3 / 2$ & $2 / 3$ & $-/ 2$ & $-/ 2$ & $-/ 1$ & $-/-$ \\
\hline & 2016-2020 & $3 / 1$ & $-/ 1$ & $-/ 2$ & $2 / 5$ & $1 / 3$ & $1 / 3$ & $3 / 4$ & $2 / 9$ & $-/ 7$ & $1 / 2$ & $1 / 2$ & $4 / 3$ & $6 / 8$ & $1 / 1$ & $2 /-$ & $3 / 3$ & $1 / 1$ & $-/ 1$ & $-/ 1$ & $-/-$ & $-/-$ \\
\hline & Bey ond 2020 & $1 / 1$ & $-/-$ & $-/ 1$ & $2 / 1$ & $1 / 1$ & $2 / 4$ & $5 / 2$ & $1 / 2$ & $-/ 2$ & $1 / 1$ & $2 / 1$ & $2 / 1$ & $2 / 3$ & $1 / 1$ & $1 /-$ & $1 / 1$ & $1 / 1$ & $-/$ & $-/-$ & $-/-$ & $-/-$ \\
\hline \multirow{2}{*}{ SRA 2014} & $2015-2020$ & $5 / 5$ & $-/ 1$ & $-/ 3$ & $4 / 8$ & $6 / 10$ & $4 / 8$ & $6 / 12$ & $4 / 15$ & $-/ 12$ & $2 / 4$ & $2 / 6$ & $5 / 5$ & $8 / 13$ & $2 / 3$ & $4 /-$ & $4 / 4$ & $6 / 7$ & $-/-$ & $-/ 2$ & $-/ 2$ & $4 / 2$ \\
\hline & Bey ond 2020 & $1 / 1$ & $-/-$ & $-/ 1$ & $2 / 4$ & $2 / 1$ & $3 / 5$ & $6 / 2$ & $1 / 2$ & $-/ 2$ & $1 / 1$ & $2 / 1$ & $2 / 1$ & $2 / 3$ & $2 / 1$ & $1 /-$ & $2 / 1$ & $2 / 2$ & $-/$ & $-/ 1$ & $-/-$ & $1 / 1$ \\
\hline \multirow{2}{*}{ SRA 2016} & 2016-2020 & $5 / 5$ & $-/ 1$ & $-/ 8$ & $5 / 8$ & $8 / 10$ & $4 / 8$ & $7 / 10$ & $4 / 17$ & $-/ 13$ & $2 / 6$ & $2 / 6$ & $5 / 5$ & $8 / 13$ & $-/-$ & $4 /-$ & $4 / 4$ & $9 / 6$ & $-/$ & $-/ 4$ & $-/ 3$ & $4 / 2$ \\
\hline & Bey ond 2020 & $3 / 1$ & $-/ 3$ & $-/ 2$ & $2 / 4$ & $3 / 2$ & $3 / 5$ & $6 / 6$ & $1 / 3$ & $-/ 2$ & $1 / 1$ & $2 / 3$ & $2 / 1$ & $5 / 5$ & $-/$ & $1 /-$ & $2 / 3$ & $12 / 6$ & $-/$ & $-/ 2$ & $-/ 3$ & $2 / 1$ \\
\hline
\end{tabular}

\section{Conclusions}

The years between 2010 and 2016 of the IoT cannot be considered successful years, because it is verified that the goals published in the first SRA in 2010 for the time period of 2010 to 2015 , only $49.57 \%$ of the goals were fulfilled (fifty-seven of the one hundred and fifteen proposed), and this is equally distributed by both "Development" and "Research" areas.

However, some effort has been made in determining the conditions for the practicality of actual IoT implementations, most of this effort is directed towards the creation of frameworks that allow the implementation of IoT in any type of real environment.
The SRAs evolution is based on the results of development and research projects with cooperation between EU and other countries, while overseen by IERC. There are ten projects from FP7 Call8, e.g., Clout Project, that was funded in 2.3M€ from EU and in $1.6 \mathrm{M} €$ from Japan. There are sixteen projects from FP7 Call5 and a long list of projects (about thirty-five) from FP7, FP6 and FP5. All the projects are finished and this is a signal of success, but there is a big area of topics and goals to be covered.

develop the most dynamic European Internet of Things ecosystem and to become a global influencer on IoT technology. The AIOTI has become a formal organization in the 2016 summer. 
IoT is a hot subject all around the globe and the AIOTI's train is leaving the platform and nobody want to miss it.

\section{Conflict of Interest}

The authors declare no conflict of interest.

\section{Acknowledgment}

This work has been supported by COMPETE: POCI-01-0145FEDER-007043 and FCT (Fundação para a Ciência e Tecnologia) within the Project Scope: UID/CEC/00319/2013.

\section{References}

[1] “About IERC," 2015, retrieved 2-12-2016: http://www.internet-of-thingsresearch.eu/about ierc.htm.

[2] O. Vermesan, P. Friess, P. Guillemin, M. Serrano, et al. "IoT Digital Value Chain Connecting Research, Innovation and Deployment", IERC Cluster, SRA, pp. 15-128, 2016.

[3] O. Vermesan, P. Friess, P. Guillemin, S. Gusmeroli, et al. "Internet of Things: Strategic Research Roadmap," Internet Things Strateg. Res. Roadmap, pp. 1-50, 2009.

[4] O. Vermesan, P. Friess, P. Guillemin, S. Gusmeroli, et al. "Internet of Things Strategic Research Roadmap," Internet Things Strateg. Res. Roadmap, pp. 9-52, 2010.

[5] M. Lerner, "Internet of Things 2012 New Horizons,” p. 360, 2012.

[6] O. Vermesan and P. Friess, Internet of Things Applications - From Research and Innovation to Market Deployment. 2014.

[7] Ashton, K., That 'internet of things' thing, RFiD Journal, vol. 22, nº 7, pp. 97-114, 2009.

[8] Coke Machine, 1998, retrieved 2-12-2016 from http://www.cs.cmu.edu/ coke

[9] O. Vermesan, P. Friess, P. Guillemin, S. Gusmeroli, et al. "Internet of Things Strategic Research Agenda", Chapter 2 in Internet of Things - Global Technological and Societal Trends, River Publishers, 2011.

[10] AIOTI, "The Alliance for Internet of Things Innovation", 2016, retrieved 212-2016 from http://www.aioti.org/ 